\title{
Dividend Sensitivity to Economic Factors, Stock Valuation, and Long-run Risk
}

\section{Revised Manuscript}

July 04, 2013

\section{Claude Bergeron}

Université du Québec (TÉLUQ)

Manuscript Number: FRL-13-48

Status date: Jun 18, 2013

Date Revision Due: July 09, 2013

Maximum number of pages: 15

Keywords:

Multifactor model; Intertemporal model; Stock valuation; CCAPM; Long-run risk.

JEL Classification: D91, G12 
Manuscript

\title{
Dividend Sensitivity to Economic Factors, Stock Valuation, and Long-run Risk
}

\begin{abstract}
In this paper, we develop a theoretical stock valuation model that takes into account the long-run sensitivity of dividends to various economic factors. Our valuation process integrates the multidimensionality of uncertainty, as well as the long-run concept of risk (recently proposed in the literature). More precisely, we demonstrate that a stock's long-run dividend growth is negatively related to its current dividend-price ratio and linearly related to $N$ sensitivity coefficients, given by the long-run sensitivity between dividends and economic factors. Then, we show that the equilibrium price of a stock is a function of its current dividend, long-run dividend growth, and $N$ risk parameters.
\end{abstract}

Keywords Multifactor model Intertemporal model Stock valuation CCAPM Longrun risk.

JEL Classification D91, G12

\section{Introduction}

There are many different ways to value stocks. Among the most popular methods employed by analysts or researchers, there is the dividend discount model, popularized by Gordon (1962), the earnings multiplier approach, developed by Basu (1977), and the residual income technique, proposed by Ohlson (1995). Following traditional models, other approaches have also emerged in the theory of stock valuation. For example, Hurley and Johnson $(1994,1998)$ extend the dividend discount model, assuming that dividends follow a Markov process. Donaldson and Kamstra (1996) extend the Gordon model, using statistical models of discounted dividend growth rates. Feltham and Ohlson (1999) provide a general version of the residual income technique in introducing risk and stochastic interest rates. Pastor and Veronesi (2003) derive a simple approach to valuing stocks in the presence of learning about average profitability. Bakshi and Chen (2005) present a stock valuation model in which the expected earnings growth rate follows a mean-reveting process. Dong and Hirshleifer (2005) generalize the model of Bakshi and Chen in proposing a stock valuation model that is not restricted to positiveearnings companies. Yee (2008) suggests a Bayesian framework for combining two or more estimates into a superior valuation estimate.

More recently, Bergeron (2011) develops a valuation model that integrates the long-run definition of consumption risk into the stock valuation process. 
According to Beeler and Campbell (2012), the long-run concept of risk has attracted a great deal of attention since the important work of Bansal and Yaron (2004).

Indeed, Bansal and Yaron argue that consumption and dividend growth rates include a small long-run component that can resolve the equity premium puzzle. Also, Bansal et al. (2005) show that long-run covariance between dividends and consumption (cash flow beta) accounts for more than $60 \%$ of the cross-sectional variation in risk premia. Moreover, Hansen et al. (2008) characterize and measure a long-run risk-return tradeoff for the valuation of financial cash flows exposed to fluctuations in macroeconomic growth. In addition, when investor horizon tends to infinity, Bansal et al. (2009) reveal that the risk of an asset is determined almost exclusively by the longrun cointegration between its dividends and consumption. Furthermore, Bansal and Kiku (2011) measure the long-run relation between asset dividends and aggregate consumption via a stochastic cointegration. ${ }^{1}$

However, none of the above mentioned studies derived a stock valuation model that integrates the multiple dimensions of long-run risk.

In this paper, we extend the work of Bergeron (2011) in integrating the multidimensionality of uncertainty, as well as the long-run concept of risk, into the stock valuation process.

More particularly, we develop a theoretical stock valuation model that takes into account the long-run sensitivity of dividends to various economic factors. Our model development is based on the intertemporal framework of the consumption capital asset pricing model (CCAPM) of Rubinstein (1976), Lucas (1978), and Breeden (1979). Our first result shows that a stock's long-run dividend growth is negatively related to its current dividend-price ratio and linearly related to $N$ sensitivity coefficients, given by the long-run covariance between dividends and economic factors. Our next result indicates that the equilibrium price of a stock is a function of its current dividend, longrun dividend growth, and $N$ risk parameters.

Compared to Bergeron (2011), our methodology presents two major differences, in addition to the integration of the multidimensionality of uncertainty. First, the constant relative risk aversion assumption via the power utility function is not required. Second, the normality hypothesis can be relaxed.

The remainder of this paper is organized in five sections. The next section presents the dividend multifactor process. The third section describes the intertemporal equilibrium framework of our model. The fourth section derives the multirisk relationships. The last section concludes the paper.

\section{The dividend multifactor process}

The basic assumption of our intertemporal model is that stock dividend growth rates are generated by a number of economic factors. More precisely, given the available information in time $t$, we assume that the dividend growth rate of stock $i$, between time $t$ and time $t+1, \tilde{g}_{i, t+1}$, is a linear function of $N$ factors as shown below:

$$
\tilde{g}_{i, t+1}=a_{i t}+b_{1 i t} \tilde{F}_{1, t+1}+b_{2 i t} \tilde{F}_{2, t+1}+\ldots+b_{N i t} \tilde{F}_{N, t+1}+\widetilde{\varepsilon}_{i, t+1},
$$

\footnotetext{
${ }^{1}$ See also Malloy et al. (2009) and Bergeron (2012).
} 
with;

$$
E_{t}\left[\tilde{\varepsilon}_{i, t+1}\right]=\operatorname{COV}_{t}\left[\tilde{\varepsilon}_{i, t+1}, \bullet\right]=0,
$$

where $a_{i t}$ is the intercept for stock $i$ at time $t ; \tilde{F}_{j, t+1}$, is the factor $j$ at time $t+1 ; b_{j i t}$, is the dividend sensitivity to factor $j$ for stock $i$ at time $t$; and $\widetilde{\varepsilon}_{i, t+1}$ is the usual random term for stock $i$ at time $t+1(j=1,2,3, \ldots, N ; i=1,2,3, \ldots, M ; t=0,1,2, \ldots, \infty)^{2}$.

To simplify the notation and the algebraic manipulations, we can also use compact matrix algebra and rewrite the basic equation (1A) in this manner

$$
\tilde{g}_{i, t+1}=a_{i t}+\mathbf{b}_{i t}^{\prime} \tilde{\mathbf{F}}_{t+1}+\widetilde{\varepsilon}_{i, t+1},
$$

where

$$
\mathbf{b}_{i t} \equiv\left[\begin{array}{l}
b_{1 i t} \\
b_{2 i t} \\
\ldots \\
b_{N i t}
\end{array}\right], \widetilde{\mathbf{F}}_{t+1} \equiv\left[\begin{array}{l}
\tilde{F}_{1, t+1} \\
\tilde{F}_{2, t+1} \\
\ldots \\
\tilde{F}_{N, t+1}
\end{array}\right] \text {, and } \mathbf{b}_{i t}^{\prime} \equiv\left[b_{1 i t} b_{2 i t} \ldots b_{N i t}\right] .
$$

Like the standard multifactor model for returns, the process expressed by equation (1) represents an approximation of the reality and the factors that we should integrate in the model or not determined by any economic theory ${ }^{3}$. Nevertheless, the rate of inflation, market dividend growth, industrial production growth and aggregate consumption growth, could certainly be considered potential factors that influence stock dividend growth rates.

Also, the usual linearity assumption adopted here is not as restrictive as it might first appear. Indeed, it is well know that any of these factors can be a nonlinear function of a variable. It could be, for example, a variable squared, the log of a variable, or any other nonlinear appropriate transformation. If the number of factors equals one $(N=1)$, and if this factor represents the aggregate consumption growth rate between time $t$ and time $t+1, \tilde{g}_{t+1}$, then equation (1A) or (1B) shows that

$$
\tilde{g}_{i, t+1}=a_{i t}+b_{C i t} \tilde{g}_{t+1}+\widetilde{\varepsilon}_{i, t+1},
$$

where $b_{C i t}$ represents the dividend sensitivity to the aggregate consumption, for stock $i$ at time $t$. Thus, for this special restrictive case, it is easy to prove ${ }^{4}$ that:

$$
b_{C i t} \equiv \operatorname{COV} V_{t}\left[\tilde{g}_{t+1}, \tilde{g}_{i, t+1}\right] / \sigma_{t}^{2}\left[\tilde{g}_{t+1}\right] .
$$

Here, the resulting coefficient $b_{C i t}$ represents, at time $t$, the covariance between the dividend growth rate of stock $i$ and the consumption growth rate, divided by the

2 The tilde $(\sim)$ indicates a random variable. Operators $E_{t}, V A R_{t}$, and $C O V_{t}$ refer respectively to mathematical expectations, variance, and covariance, where index $t$ implies that we consider the available information at time $t$. The second line of equation (1A) simply supposes that the random noise term $(\varepsilon)$ presents a zero mean value and a zero correlation value with any other variables.

${ }^{3}$ See, for example, Elton et al. (2008), Chapter 8.

${ }^{4}$ If $x, y$ and e represent general variables, and if $y=a+b x+e$, where $\operatorname{COV}(x, e)=0$, then $\operatorname{COV}(x, y)=$ $\operatorname{COV}(x, a+b x+e)=\operatorname{COV}(x, x) b$. Therefore: $b=\operatorname{COV}(x, y) / \sigma^{2}(x)$. 
variance of the consumption growth rate. In this sense, it is very similar to what Bansal et al. (2002, p. 5) call dividend beta or what Abel (1999) identifies as the key determinant of the risk premia (see also Bergeron, 2011).

Another special case of our model can also be proposed if we accept, as in Bansal et al. (2005), that the relationship between dividend and consumption growth rates is given by the following linear function

$$
\tilde{g}_{i, t+1}=a_{i t}+b_{i t} \tilde{x}_{t}+\widetilde{\varepsilon}_{i, t+1},
$$

in which variable $\tilde{x}_{t}$ represents the K-periods average of future consumption

$$
\tilde{x}_{t} \equiv(1 / K) \sum_{k=1}^{K} \tilde{g}_{t+k}
$$

where $\tilde{g}_{t+k}$ is the aggregate consumption growth rate between time $t+k-1$ and time $t+k$. For this case, it is now easy to prove (see note 4 ) that

$$
b_{i t} \equiv \operatorname{COV}{ }_{t}\left[\tilde{x}_{t}, \tilde{g}_{i, t+1}\right] / \sigma_{t}^{2}\left[\tilde{x}_{t}\right],
$$

where the resulting coefficient $b_{i t}$ represents, at time $t$, the covariance between the dividend growth rate of stock $i$ and the K-periods average of future consumption, divided by the variance of the previous variable. Therefore, for this particular case, we can argue that the sensitive coefficient is relatively close to what Bansal et al. (2002, 2005) call cash flow beta 5 .

\section{The intertemporal equilibrium framework}

Following Bergeron (2011) and others before $^{6}$, our intertemporal equilibrium framework considers a closed economy populated by identical agents. At time $t$, each agent maximizes the time-separable utility function ${ }^{7}$.

$$
U\left(C_{t}\right)+E_{t} \sum_{s=1}^{\infty} \delta^{s} U\left(\tilde{C}_{t+s}\right)
$$

subject to resource constraints, where $\delta$ is the subjective discount factor $(0<\delta<1)$, $C_{t}$ is the aggregate consumption at time $t, \tilde{C}_{t+s}$ is the random aggregate consumption at time $t+s$, and $U(\bullet)$ is an increasing concave and derivable function $(s=1,2, \ldots, \infty)$.

At equilibrium, each agent found the solution of the above problem and the resulting price of asset $i$ at time $t, P_{i t}$, is (see Rubinstein, 1976)

$$
P_{i t}=E_{t} \sum_{s=1}^{\infty} \delta^{s} \frac{U^{\prime}\left(\tilde{C}_{t+s}\right)}{U^{\prime}\left(C_{t}\right)} \tilde{D}_{i, t+s},
$$

\footnotetext{
${ }^{5}$ See, in particular, Bansal et al. (2002, p. 5 and p. 6).

${ }^{6} \mathrm{See}$, for instance, Abel (1999).

${ }^{7}$ In appendix B, we relax the restrictive time-separable utility assumption.
} 
where $\tilde{D}_{i, t+s}$ represents the dividend of asset $i$ at time $t+s .{ }^{8}$ Equation (3) reveals that the price of a stock is equivalent to the present value of all future dividends, in which the stochastic discount factor for each future dividend corresponds to the intertemporal marginal rate of substitution between consumption at time $t$ and consumption at time $t+s, \tilde{M}_{t+s}$, that is: $\tilde{M}_{t+s} \equiv \delta^{s} U^{\prime}\left(\tilde{C}_{t+s}\right) / U^{\prime}\left(C_{t}\right)$. With this notation, the equilibrium price becomes

$$
P_{i t}=E_{t} \sum_{s=1}^{\infty} \tilde{M}_{t+s} \tilde{D}_{i, t+s} .
$$

Since the dividend of stock $i$ at time $t, D_{i t}$, is known with the current information, it can thus be passed through the conditional expectation operator and be multiplied on each side, to obtain

$$
P_{i t}=D_{i t} E_{t} \sum_{s=1}^{\infty} \tilde{M}_{t+s} \tilde{D}_{i, t+s} / D_{i t}
$$

or

$$
P_{i t}=D_{i t} E_{t}\left[\tilde{Y}_{i t}\right]
$$

where variable $\tilde{Y}_{i t}$ is defined as follows: $\tilde{Y}_{i t} \equiv \sum_{s=1}^{\infty} \tilde{M}_{t+s} \tilde{D}_{i, t+s} / D_{i t}$. To simplify the notation, we can also express equation (6) in this way

$$
P_{i t}=D_{i t} \theta_{i t}
$$

where $\theta_{i t} \equiv E_{t}\left[\tilde{Y}_{i t}\right]$. Furthermore, if the sequence of variables $\tilde{Y}_{i t}(t=0,1,2, \ldots, \infty)$ is independent and identically distributed (i.i.d.), then

$$
P_{i t}=D_{i t} \theta_{i} \text {. }
$$

Therefore, given the available information at time $t$, we have

$$
\tilde{P}_{i, t+1}=\tilde{D}_{i, t+1} \theta_{i}
$$

where $\widetilde{P}_{i, t+1}$ represents the random price of stock $i$ at time $t+1$.

Consequently, as in Bergeron (2011), but without the restrictive assumption of a constant relative risk aversion via the power utility function, it is easy to demonstrate that the random future price of a stock is directly and stochastically related with its next dividend payment, or, if we prefer, that dividends and prices are perfectly cointegrated.

\section{The multiple dimensions of long-run risk valuation}

In this section, we show that the multiple dimensions of long-run risk influence the theoretical value of stock prices. First, we derive the expected dividend growth rate of a stock for one period and one factor. Second, we express the expected dividend growth

\footnotetext{
${ }^{8}$ The premium $\left(U^{\prime}\right)$ is a derivative of a function.
} 
rate for one period and many factors. Third, we express the expected dividend growth rate for many periods and many factors. Finally, we introduce the current dividendprice ratio to deduce the corresponding stock price value.

Actually, our model development is similar to any multifactor model that, given the $N$ factors process, derives asset prices from equilibrium conditions (see, for example, the Arbitrage Pricing Theory, APT, of Ross, 1976) ${ }^{9}$.

\subsection{Expected dividend growth with one period and one factor}

By induction, for one period, the resulting stock price expressed by equation (4), becomes $^{10}$

$$
P_{i t}=E_{t}\left[\tilde{M}_{t+1}\left(\tilde{D}_{i, t+1}+\tilde{P}_{i, t+1}\right)\right] .
$$

Substituting equations (8) and (9) into equation (10) gives

$$
D_{i t} \theta_{j}=E_{t}\left[\tilde{M}_{t+1}\left(\tilde{D}_{i, t+1}+\tilde{D}_{i, t+1} \theta_{i}\right)\right],
$$

or, after manipulations

$$
1=E_{t}\left[\tilde{M}_{t+1}\left(1+\tilde{g}_{i, t+1}\right)\left(1+\theta_{i}^{-1}\right)\right] .
$$

This permits us to exhibits a particular form of the Euler equation in which the central random variables are driven by aggregate consumption and dividends. On the other side, if we accept the existence of a riskless asset, then the standard form of the Euler equation (with returns) shows that

$$
1=E_{t}\left[\tilde{M}_{t+1}\left(1+R_{F, t+1}\right)\right]
$$

where $R_{F, t+1}$ represents the risk-free rate of return, between $t$ and $t+1^{11}$. Equation (12) minus equation (13), yield, after manipulations

$$
0=E_{t}\left[\tilde{M}_{t+1}\left\{\left(1+\tilde{g}_{i, t+1}\right)\left(1+\theta_{i}^{-1}\right)-\left(1+R_{F, t+1}\right)\right\}\right] .
$$

Taking the expectation on each side of equation (14A) allows us to release the index $t$ of the conditional operator, to shows

$$
0=E\left[\tilde{M}_{t+1}\left\{\left(1+\tilde{g}_{i, t+1}\right)\left(1+\theta_{i}^{-1}\right)-\left(1+R_{F, t+1}\right)\right\}\right] .
$$

Integrating the definition of covariance into equation (14B) indicates that:

$$
\begin{aligned}
& \operatorname{COV}\left[\tilde{M}_{t+1},\left(1+\tilde{g}_{i, t+1}\right)\left(1+\theta_{i}^{-1}\right)-\left(1+R_{F, t+1}\right)\right]= \\
& -E\left[\tilde{M}_{t+1}\right] E\left[\left(1+\tilde{g}_{i, t+1}\right)\left(1+\theta_{i}^{-1}\right)-\left(1+R_{F, t+1}\right)\right],
\end{aligned}
$$

while the properties of covariance combined to equation (13) implies that

\footnotetext{
${ }^{9}$ See, also, Merton (1973) or Fama and French (1996).

${ }^{10}$ See Huang and Litzenberger (1988, page 202).

${ }^{11}$ See Huang and Litzenberger (1988, page 205).
} 
Dividend Sensitivity to Economic Factors, Stock Valuation, and Long-run Risk

$$
E\left[1+\tilde{g}_{i, t+1}\right]\left(1+\theta_{i}^{-1}\right)\left(1+R_{F, t+1}\right)^{-1}=1-\operatorname{COV}\left[\tilde{M}_{t+1}, \tilde{g}_{i, t+1}\right]\left(1+\theta_{i}^{-1}\right) .
$$

Thus, in equilibrium, the expected divided growth of any stock satisfied

$$
E\left[1+\tilde{g}_{i, t+1}\right]=\left(1+R_{F, t+1}\right) /\left(1+\theta_{i}^{-1}\right)-\operatorname{COV}\left[\tilde{M}_{t+1}, \tilde{g}_{i, t+1}\right]\left(1+R_{F, t+1}\right) .
$$

In short, for one period, the price equilibrium condition given by equation (10) also involve that the expected dividend growth rate of a stock, should respect the onedimensional relationship expressed by equation (17).

\subsection{Expected dividend growth with one period and many factors}

To extend toward a multidimensional expression, let us first introduce the multifactor model formulated by equation (1B) into equation (17)

$$
E\left[1+\tilde{g}_{i, t+1}\right]=\left(1+R_{F, t+1}\right) /\left(1+\theta_{i}^{-1}\right)-\left(1+R_{F, t+1}\right) \operatorname{COV}\left[\tilde{M}_{t+1}, a_{i t}+\mathbf{b}_{i t}^{\prime} \tilde{\mathbf{F}}_{t+1}+\tilde{\varepsilon}_{i, t+1}\right] .
$$

Using proprieties of covariance, equation (18) can thus be arranged and presented as a multilinear function. That is

$$
E\left[\tilde{G}_{i, t+1}\right]=\lambda_{o t}\left(1+\theta_{i}^{-1}\right)^{-1}+\lambda_{1 t} b_{1 i t}+\lambda_{2 t} b_{2 i t}+\ldots+\lambda_{N t} b_{N i t},
$$

with

$$
\begin{aligned}
& \tilde{G}_{i, t+1} \equiv\left(1+\tilde{g}_{i, t+1}\right), \lambda_{o t} \equiv\left(1+R_{F, t+1}\right), \\
& \lambda_{j t} \equiv-\left(1+R_{F, t+1}\right) C O V_{t}\left[\tilde{M}_{t+1}, \tilde{F}_{j, t+1}\right], \text { for every } j=1,2, \ldots, N .
\end{aligned}
$$

Equation (19) represents an equilibrium condition when dividend growth rates are generated by $N$ factors, on a single period. As the APT principal prediction, it shows that the equilibrium relationship can be described by a $N$-dimensional hyper plane.

Besides, if $N$ equals one, and if the factor chosen is the aggregate consumption growth rate, then equation (19) shows that the only sensitive coefficient that influences the equilibrium dividend growth rate is the dividend beta (introduced before). In addition, if the utility function is definite by a power utility function, then, for this special restrictive case, the marginal rate of substitution, between consumption at time $t$ and consumption at time $t+1$, is negatively related with the consumption growth. As a result, the relationship between the expected dividend growth rate and dividend beta is necessarily positive, since $\lambda_{1 t}$ is positive (see Appendix A).

\subsection{Expected dividend growth with many periods and many factors}

For many periods, summing from $t=0$ to $t=T-1$, yields

$$
\sum_{t=0}^{T-1} E\left[\tilde{G}_{i, t+1}\right]=\sum_{t=0}^{T-1}\left(\lambda_{0 t}\left(1+\theta_{i}^{-1}\right)^{-1}+\lambda_{1 t} b_{1 i t}+\lambda_{2 t} b_{2 i t}+\ldots+\lambda_{N t} b_{N i t}\right),
$$

or 


$$
\sum_{t=0}^{T-1} E\left[\tilde{G}_{i, t+1}\right]=\left(1+\theta_{i}^{-1}\right)^{-1} \sum_{t=0}^{T-1} \lambda_{0 t}+\sum_{t=0}^{T-1} \lambda_{1 t} b_{1 i t}+\sum_{t=0}^{T-1} \lambda_{2 t} b_{2 i t}+\ldots+\sum_{t=0}^{T-1} \lambda_{N t} b_{N i t} .
$$

Multiplying by $\sum_{t=0}^{T-1} \lambda_{1 t}, \sum_{t=0}^{T-1} \lambda_{2 t}, \ldots$, and $\sum_{t=0}^{T-1} \lambda_{N t}$ on each side of equation (21), gives

$$
\sum_{t=0}^{T-1} E\left[\widetilde{G}_{i, t+1}\right]=\left(1+\theta_{i}^{-1}\right)^{-1} \sum_{t=0}^{T-1} \lambda_{o t}+\sum_{t=0}^{T-1} \lambda_{1 t} \sum_{t=0}^{T-1} w_{1 t} b_{1 i t}+\ldots+\sum_{t=0}^{T-1} \lambda_{N t} \sum_{t=0}^{T-1} w_{N t} b_{N i t},
$$

where

$$
w_{j t} \equiv \lambda_{j t} / \sum_{t=0}^{T-1} \lambda_{j t}, \text { with } \sum_{t=0}^{T-1} w_{j t}=1(\forall j=1,2, \ldots N) .
$$

Therefore, multiplying by $T^{-1}$ on both side of equation (22) implies that

$$
\bar{G}_{i}=\lambda_{0}\left(1+\theta_{i}^{-1}\right)^{-1}+\lambda_{1} \bar{b}_{1 i}+\lambda_{2} \bar{b}_{2 i}+\ldots+\lambda_{N} \bar{b}_{N i},
$$

with

$$
\bar{G}_{i} \equiv 1+\bar{g}_{i}, \quad \bar{g}_{i} \equiv \sum_{t=0}^{T-1} E\left[\tilde{g}_{i, t+1}\right] / T, \quad \lambda_{o} \equiv \sum_{t=0}^{T-1} \lambda_{o t} / T,
$$

and

$$
\lambda_{i} \equiv \sum_{t=0}^{T-1} \lambda_{i t} / T, \quad \bar{b}_{j i} \equiv \sum_{t=0}^{T-1} w_{j t} b_{j i t} \quad(\forall j=1,2, \ldots N) .
$$

Here, $\bar{g}_{i}$ (or $\bar{G}_{i}$ ) can be viewed as the arithmetic average (over many periods) of the expected dividend growth rates of stock $i$, or, to put it differently, the long-run expected dividend growth rate of stock $i$. In addition, $\bar{b}_{1 i}, \bar{b}_{2 i}, \ldots$, and $\bar{b}_{N i}$ can be viewed, respectively, as the weighted average of sensitive coefficients $b_{1 i t}, b_{2 i t}, \ldots$, and $b_{N i t}$ (for $t=1,2, \ldots ., T-1)$.

Equation (23A) shows that a stock's long-run dividend growth is linearly related to $N$ sensitivity coefficients, given by the long-run sensitivity between dividends and economic factors. Besides, if $N=1$ and if this factor is $\tilde{g}_{t+1}$ (the aggregate consumption growth rate), then equation (23A) can be reduced to the following expression

$$
\bar{G}_{i}=\lambda_{o}\left(1+\theta_{i}^{-1}\right)^{-1}+\lambda_{1} \bar{b}_{1 i},
$$

where

$$
b_{1 i t}=\operatorname{COV}\left[\tilde{g}_{t+1}, \tilde{g}_{i, t+1}\right] / \sigma^{2}\left[\tilde{g}_{t+1}\right], \lambda_{1}=\sum_{t=0}^{T-1} \lambda_{1 t} / T \text {, and } \bar{b}_{1 i}=\sum_{t=0}^{T-1} w_{1 t} b_{1 i t} .
$$

For this special case, parameter $\bar{b}_{1 i}$ is estimated by its long run covariance between dividends and consumption (its long-run dividend beta). Thus, if we accept that the long-run covariance between dividends and consumption represents a good measure of risk, as many authors claim (see, for example, Bansal and Yaron, 2004; Bansal et al., 2005; Bansal et al., 2009; Bansal and Kiku, 2011; and Bergeron, 2011) then equation (23B) implies that the expected dividends growth, on the long run, is linearly related to risk. In addition, if we assume that the representative agent has a power utility function 
then the relationship between dividend growth and risk, is also positive, since $\lambda_{1 t}$ and (then) $\lambda_{1}$ are positive.

As noted by Bergeron (2011), the link between dividend growth, current dividend, and risk (in its standard form) is not a new subject in finance. Indeed, it is generally accepted that big old firms that already pay generous dividends and have low risk present low expected dividend growth, in the long-run ${ }^{12}$. Moreover, many authors observed a negative relationship between dividend yield and dividend growth or between dividend and risk, in addition to a positive correlation between dividend growth and risk. ${ }^{13}$ The belief can be rationalized in this manner: if firms are risk averse and cautious, then those operating in a high level of uncertainty will pay lower dividends to have enough retained earnings for bad earnings years (see Hoberg and Prabhala, 2009). Consequently, in a high uncertainty context, firms should display a high measure of risk, a low current dividend (relative to earnings, price or future dividends), and a high expected dividend growth simultaneously.

In sum, with the one dimensional special case described by equation (23B), it is easy to see that our model is consistent with the above proposals concerning the link between dividend growth, dividend yield, and risk (on the long-run) ${ }^{14}$.

Nevertheless, in its general form, equation (23) shows that the relationship between dividend growth and risk, on the long-run, can be easily extended to multiple dimensions.

\subsection{Dividend-price ratio and equilibrium stock price}

At time $t=0$, equation (8) establishes that the current dividend-price ratio $\left(D_{i 0} / P_{i 0}\right.$ ) equals $\theta_{i}^{-1}$. This permits us to write that

$$
\bar{G}_{i}=\lambda_{o}\left(1+D_{i 0} / P_{i 0}\right)^{-1}+\lambda_{1} \bar{b}_{1 i}+\lambda_{2} \bar{b}_{2 i}+\ldots+\lambda_{N} \bar{b}_{N i},
$$

or that

$$
\bar{G}_{i}=\lambda_{o}\left(1+D_{i 0} / P_{i 0}\right)^{-1}+\lambda^{\prime} \overline{\mathbf{b}}_{i}
$$

where, $\lambda^{\prime} \equiv\left[\begin{array}{lll}\lambda_{1} & \lambda_{2} \ldots \lambda_{N}\end{array}\right]$, and $\overline{\mathbf{b}}_{i} \equiv\left[\begin{array}{l}\bar{b}_{1 i} \\ \bar{b}_{2 i} \\ \ldots \\ \bar{b}_{N i}\end{array}\right]$.

In this manner, equation (24) shows that a stock's long-run dividend growth is negatively related to its current dividend-price ratio and linearly related to $N$ sensitivity coefficients, given by the long-run sensitivity between dividends and economic factors.

The introduction of the dividend-price ratio in the relationship just confirms the following proposal: if firms are effectively risk averse and cautious, then those operating in a high level of uncertainty will display a high measure of risk, a low

\footnotetext{
${ }^{12}$ See Bergeron (2011), Brav et al. (2005) or Grullon et al. (2002).

${ }^{13}$ See, for example, Beaver et al. (1970) or Senbet and Thompson (1982).

${ }^{14}$ The one dimensional special case expressed by equation (23B) is also consistent with equation (24) in Bergeron (2011).
} 
dividend-price ratio and a high expected dividend growth simultaneously. The introduction of the ratio also permits us to express the theoretical value of a stock with a simple formula. Indeed, rearranging equation (24) gives

$$
P_{i 0}=\frac{\bar{G}_{i}-\lambda^{\prime} \overline{\mathbf{b}}_{i}}{\lambda_{o}+\lambda^{\prime} \overline{\mathbf{b}}_{i}-\bar{G}_{i}} D_{i 0},
$$

or, if we prefer

$$
P_{i 0}=\frac{1+\bar{g}_{i}-\lambda^{\prime} \overline{\mathbf{b}}_{i}}{\bar{R}_{F}+\lambda^{\prime} \overline{\mathbf{b}}_{i}-\bar{g}_{i}} D_{i 0},
$$

with

$$
\bar{R}_{F} \equiv \sum_{t=0}^{T-1} R_{F t} / T
$$

The last formula indicates that the equilibrium price of a stock is a function of its current dividend, long-run dividend growth, and $N$ long-run dividend sensitivity parameters.

Under conditions of certainty (betas equal zero), equation (25) is analogous to the classic Gordon model, and the equilibrium stock price is a function of its current dividend and long-run dividend growth, only. Under conditions of uncertainty, the scalar product given by $\lambda^{\prime} \overline{\mathbf{b}}_{i}$ has a negative effect on price. Thus, we can maintain that this value represents the risk adjustment factor, while sensitivity vector $\overline{\mathbf{b}}_{i}$ represents a multidimensional risk measure.

As a result, the theoretical value of a stock appears to be a function of its current dividend, long-run dividend growth, and $N$ risk parameters, given by the long-run sensitivity of dividends to various economic factors.

\section{Conclusion}

In this paper, we showed that the relationship between dividends, stock prices, and long-run risks, is easily extended to a multidimensional framework. In particular, after assuming that the dividend growth rate on any stock is a function of $N$ variables, we showed that a stock's long-run dividend growth is negatively related to its current dividend-price ratio and linearly related to $N$ sensitivity coefficients, given by the longrun sensitivity between dividends and economic factors. Then, we showed that the equilibrium price of a stock is determined by its current dividend, long-run dividend growth, and $N$ risk parameters. In all, our extension model suggests that the multidimensionality of long-run risk should be considered in assessing the theoretical value of a firm.

In the construction of our model, we first used the standard time-separable utility assumption. Afterward, we relaxed this restrictive assumption in appendix B, using habit formation. It could be interesting, for a future model, to generalize the utility function, in using, in addition, the Kreps and Porteus (1978) recursive utility function ${ }^{15}$.

${ }^{15}$ See, also, Strzalecki (2013). 
Furthermore, it could be interesting, for future research, to develop an empirical test of our model ${ }^{16}$.

\section{Appendix A}

In this appendix, we demonstrate that coefficient $\lambda_{1 t}$, of equation (19), is necessarily positive, if we suppose that $N=1, \tilde{F}_{1, t+1}=\tilde{g}_{t+1}$, and $\tilde{M}_{t+1}$ is given by a power utility function. Indeed, with a power utility function we know that $\tilde{M}_{t+1}=\delta\left(1+\tilde{g}_{t+1}\right)^{-\gamma}$, where $\gamma>0$ and $\delta>0$ (see, for example, Bansal and Kiku, 2011). Thus, $\lambda_{1 t}$ is necessarily positive, since the covariance term is necessarily negative:

$$
\left.\lambda_{1 t} \equiv-\left(1+R_{F, t+1}\right) \operatorname{COV} V_{t}\left[\tilde{M}_{t+1}, \tilde{F}_{1, t+1}\right]=-\left(1+R_{F, t+1}\right) \operatorname{COV} V_{t}\left[\left(1+\tilde{g}_{t+1}\right)^{-\gamma}, \tilde{g}_{t+1}\right)\right] \delta .
$$

\section{Appendix B}

In this appendix, we relax the restrictive time-separable utility assumption, using habit formation. Here, at time $t$, each agent maximizes the non-separable utility function ${ }^{17}$

$$
U\left(C_{t}^{*}\right)+E_{t} \sum_{s=1}^{\infty} \delta^{s} U\left(\tilde{C}_{t+s}^{*}\right)
$$

subject to resource constraints, with $C_{t}^{*}=C_{t}-z_{t}, z_{t}=\lambda C_{t-1}, \tilde{C}_{t+s}^{*}=\tilde{C}_{t+s}-\tilde{z}_{t+s}$, and $\tilde{z}_{t+s}=\lambda \tilde{C}_{t+s-1}^{*}$, where $z_{t}$ and $\tilde{z}_{t+s}$ represent the habit, modeled as a fraction of $C_{t-1}$ and $\tilde{C}_{t+s-1}$. At equilibrium, each agent found the solution of the above problem and the resulting price of asset $i$, at time $t$, is now (see Athanasoulis and Sussman, 2007)

$$
P_{i t}=E_{t} \sum_{s=1}^{\infty} \delta^{s} \frac{U^{\prime}\left(\tilde{C}_{t+s}^{*}\right)}{U^{\prime}\left(C_{t}^{*}\right)} \tilde{D}_{i, t+s}=E_{t} \sum_{s=1}^{\infty} \tilde{M}_{t+s}^{*} \tilde{D}_{i, t+s},
$$

with $\tilde{M}_{t+s}^{*} \equiv \delta^{s} U^{\prime}\left(\tilde{C}_{t+s}^{*}\right) / U^{\prime}\left(C_{t}^{*}\right)$. Thus, from equation (4) to equation (9), we have

$$
\widetilde{P}_{i, t+1}=\tilde{D}_{i, t+1} \theta_{i}^{*}
$$

where $\theta_{i}^{*}$ is equivalent to $\theta_{i}$ except that $\tilde{M}_{t+s}^{*}$ replace $\tilde{M}_{t+s}$. By induction, for one period, the resulting stock price expressed by equation (B.2), becomes

$$
P_{i t}=E_{t}\left[\tilde{M}_{t+s}^{*}\left(\tilde{D}_{i, t+1}+\tilde{P}_{i, t+1}\right)\right] .
$$

From equation (10) to equation (17), we can write

$$
E\left[1+\tilde{g}_{i, t+1}\right]=\left(1+R_{F, t+1}\right) /\left(1+1 / \theta_{i}^{*}\right)-\operatorname{COV}\left[\tilde{M}_{t+1}^{*}, \tilde{g}_{i, t+1}\right]\left(1+R_{F, t+1}\right) .
$$

\footnotetext{
${ }^{16}$ In appendix C, we present an exploratory empirical application of our model.

${ }^{17}$ See Athanasoulis and Sussman (2007). In particular, see section 4.
} 
Introducing the multifactor model formulated by equation (1B) into equation (B.5), yields

$$
E\left[\tilde{G}_{i, t+1}\right]=\left(1+R_{F, t+1}\right) /\left(1+1 / \theta_{i}^{*}\right)-\left(1+R_{F, t+1}\right) \operatorname{COV}\left[\tilde{M}_{t+1}^{*}, a_{i t}+\mathbf{b}_{i t}^{\prime} \tilde{\mathbf{F}}_{t+1}+\widetilde{\varepsilon}_{i, t+1}\right] .
$$

Using properties of covariance, equation (B.6) can now be arranged and presented as the following multilinear function

$$
E\left[\tilde{G}_{i, t+1}\right]=\lambda_{o t}\left(1+1 / \theta_{i}^{*}\right)^{-1}+\lambda_{1 t}^{*} b_{1 i t}+\lambda_{2 t}^{*} b_{2 i t}+\ldots+\lambda_{N t}^{*} b_{N i t},
$$

with, $\lambda_{j t}^{*} \equiv-\left(1+R_{F, t+1}\right) C O V_{t}\left[\tilde{M}_{t+1}^{*}, \tilde{F}_{j, t+1}\right]$, for every $j=1,2, \ldots, N$. Finally, from equation (20) to equation (25), we can obtain our last result. That is:

$$
P_{i 0}=\frac{1+\bar{g}_{i}-\lambda_{*}^{\prime} \overline{\mathbf{b}}_{i}}{\bar{R}_{F}+\lambda_{*}^{\prime} \overline{\mathbf{b}}_{i}-\bar{g}_{i}} D_{i 0},
$$

where $\lambda_{*}^{\prime}$ is equivalent to $\lambda^{\prime}$ except that $\tilde{M}_{t+s}^{*}$ replace $\tilde{M}_{t+s}$.

\section{Appendix C}

In appendix $\mathrm{C}$, we present an exploratory application of our model that could be helpful for future empirical research. Our short exposal uses the data presented in Bansal et al. (2005). We also use their cross-sectional regression techniques, described in their section $B$.

More precisely, we begin our exploration by examining the ability of our model to explain the cross section of dividend growth rates (instead than returns). The cross sectional restriction is given by equation (24), in its simplest form, that is to say, when $N=1, \widetilde{F}_{1, t+1}=\tilde{g}_{t+1}$ (the aggregate consumption growth rate) and $D_{i 0} / P_{i 0}=D Y$, where $D Y$ represents the aggregate dividend yield. Put differently, the cross sectional restriction is given by

$$
\bar{G}_{i}=\lambda_{o}(1+D Y)^{-1}+\lambda_{1} \bar{b}_{1 i},
$$

where parameters and variables are similar to equation (23B), with $\theta_{i}^{-1}=D Y^{18}$. In this manner, we can write that

$$
\bar{G}_{i}=\lambda_{0}+\lambda_{1} \bar{b}_{1 i},
$$

with $\lambda_{0} \equiv \lambda_{o}(1+D Y)^{-1}$.

Here, $\lambda_{0}$ and $\lambda_{1}$ represent the cross sectional parameters of the model. The data for variable $\bar{G}_{i}$ is issued from Table II (p. 1650) of Bansal et al. (2005). Table II presents descriptive statistics for the cash flow (dividend) growth rates on 30 portfolios. The data for variable $\bar{b}_{1 i}$ is issued from Table III (p. 1651) of Bansal et al. (2005). Table III

\footnotetext{
18 Assuming that every stock has the same dividend yield permits us to remove the effect of dividend policies and to concentrate our attention on the effect of long-run risk (as in Bansal et al., 2005).
} 
presents descriptive statistics of two alternative measures, $\gamma_{i}$ and $\beta_{i g}$, of the cash flow beta, for the 30 portfolios. ${ }^{19}$ The measure $\gamma_{i}$ is obtained from a projection of cash flow growth rates on a moving sum of lagged consumption growth. The measure $\beta_{i g}$ is obtained from regressing the cash flow innovation on the consumption innovation.

Our Table 1 and Table 2 present results for cross-sectional regression, utilizing the portfolio set. Parameter estimates and statistic coefficients are obtained in a single step via ordinary least squares.

In Table 1, we report results of a cross-sectional regression of average real dividend growth rates plus one $\left(G_{i}\right)^{20}$ on the cash flow betas estimated by parameter $\gamma_{i}$.

\section{Table 1}

Cross-sectional evidence for dividends and risk, using lagged consumption growth

The dependent variable is $G_{i}$ and the independent variable is $\gamma_{i}$

$\begin{array}{llll} & \text { Coefficient } & \text { Standard error } & \text { T-Statistic } \\ \text { Constant }\left(\lambda_{0}\right) & 0.99909 & 0.00126 & 794.74 \\ \text { Slope }\left(\lambda_{1}\right) & 0.00254 & 0.00031 & 8.27 \\ \text { R-Squared } & 0.70943 & & \\ \text { F-Statistic } & 68.36 & & \end{array}$

In Table 2, we repeat the exercise with cash flow betas estimated by parameter $\beta_{i g}$.

Table 2

Cross-sectional evidence for dividends and risk, using consumption innovation

The dependent variable is $G_{i}$ and the independent variable is $\beta_{i g}$

$\begin{array}{llll} & \text { Coefficient } & \text { Standard error } & \text { T-Statistic } \\ \text { Constant }\left(\lambda_{0}\right) & 0.99789 & 0.00157 & 635.21 \\ \text { Slope }\left(\lambda_{1}\right) & 0.00162 & 0.00025 & 6.56 \\ \text { R-Squared } & 0.60551 & & \\ \text { F-Statistic } & 42.98 & & \end{array}$

The results indicate that for both measures of cash flow risk (or long-run risk) the linear relationship is positive and strongly significant. When risk is measured by $\gamma_{i}$, the slope (or parameter $\lambda_{1}$ ) is estimated as 0.00254 with a standard error of 0.00031 and a Tstatistic of 8.27 . When risk is measured by $\beta_{i g}$, the slope is now estimated as 0.00162 with a standard error of 0.00025 and a T-Statistic of 6.56. In both cases, the model explains a considerable portion of the cross-sectional variation in dividend growth rates;

\footnotetext{
19 These measures of risk are similar to the projection coefficient presented in our equation (1D).

${ }^{20}$ Note that dividend growth data are converted from log differences to ordinary growth rates (plus one).
} 
when risk is measured by $\gamma_{i}$, the R-squared is $70.94 \%$, and when risk is measured by $\beta_{i g}$, the R-squared is $60.55 \%$. In addition, in both cases, the constant (or parameter $\lambda_{0}$ ) is near one, which is consistent with our model ${ }^{21}$.

Overall, our exploratory empirical results allow us to expect that a more sophisticated test will support our theoretical model.

\section{References}

Abel., A., 1999. Risk premia and term premia in general equilibrium. Journal of Monetary Economics 43, 3-33.

Athanasoulis, S.G., Sussman, O., 2007. Habit formation and the equity-premium puzzle: a skeptical view. Annals of Finance 3, 193-212.

Bansal, R., Dittmar, R.F., Kiku, D., 2009. Cointegration and consumption risks in asset returns. Review of Financial Studies 22, 1343-1375.

Bansal, R., Dittmar, R.F., Lundblad, C., 2002. Consumption, dividends, and the cross-section of equity returns. Working paper, Duke University.

Bansal, R., Dittmar, R.F., Lundblad, C., 2005. Consumption, dividends, and the cross-section of equity returns. The Journal of Finance 60, 1639-1672.

Bansal, R., Kiku, D., 2011. Cointegration and Long-Run Asset Allocation. Journal of Business and Economic Statistics 29, 161-173.

Bansal, R., Yaron, A., 2004. Risks for the long run: A potential resolution of asset pricing puzzles. The Journal of Finance 59, 1481-1509.

Bakshi, G., Chen, Z., 2005. Stock valuation in dynamic economies. Journal of Financial Markets 8, 111151.

Basu, S., 1977. Investment performance of common stock in relation to their price earnings ratios: a test of efficient market hypothesis. The Journal of Finance 32, 663-678.

Beaver, W., Kettler, P., Scholes, M., 1970. The association between market determined and accounting determined risk measures. Accounting Review 45, 654-682.

Beeler, J., Campbell, J., 2012. The long-run risks model and aggregate asset prices: an empirical assessment. Critical Finance Review, 1 141-182.

Bergeron, C., 2011. Dividend growth, stock valuation, and long-run risk. Journal of Economics and Finance (in press).

Bergeron, C., 2012. Dividend policy and consumption risk. International Journal of Economics and Finance 4 (8), 1-11.

Brav, A., Graham, J.R., Harvey, C.R., Michaely, R., 2005. Payout policy in the $21^{\text {st }}$ century. Journal of Financial Economics 77, 483-527.

Breeden, D.T., 1979. An intertemporal asset pricing model with stochastic consumption and investment opportunities. Journal of Financial Economics 7, 265-296.

Donaldson, R.G., Kamstra, M., 1996. A new dividend forecasting procedure that rejects bubbles in asset prices. Review of Financial Studies 9, 333-383.

Dong, M., Hirshleifer, D., 2005. A generalized earnings-based stock valuation model. The Manchester School 73, 1-31.

\footnotetext{
${ }^{21}$ According to equations (19) and (C.2), the constant should be an estimation of one plus the free risk rate divided by one plus the aggregate dividend yield.
} 
Dividend Sensitivity to Economic Factors, Stock Valuation, and Long-run Risk

Elton, E. J., Gruber, M.J., Brown, S.J., Goetzmann, W.N., 2008. Modern Portfolio Theory and Investment Analysis (Ed. 8). John Wiley \& Sons, New York.

Fama, E.F., French, K.R., 1996. Multifactor explanations of asset pricing anomalies. The Journal of Finance $51(1), 55-84$

Feltham, G.A., Ohlson, J.A., 1999. Residual earnings valuation with risk and stochastic interest rates. The Accounting Review 74, 165-183.

Gordon, M., 1962. The investment, financing, and valuation of the corporation. Homewood, Ill, Irwin.

Grullon G., Michaely, R., Swaminathan, B., 2002. Are dividend changes a sign of maturity? Journal of Business 75, 387-424.

Hansen, L.P., Heaton, J.C., Li, N., 2008. Consumption strikes back?: Measuring long-run risk. Journal of Political Economy 116, 260-302.

Hoberg, G., Prabhala, N.R., 2009. Disappearing dividends, catering, and risk. Review of Financial Studies 22, 79-116.

Huang, C-F., Litzenberger R.H., 1988. Foundations for financial economics. New York: North-Holland.

Hurley, W.J., Johnson, L.D., 1994. A realistic dividend valuation model. Financial Analyst Journal 50 (4), 50-54.

Hurley, W.J., Johnson, L.D., 1998. Generalized Markov dividend discount models. Journal of Portfolio Management 24 (1), 27-31.

Kreps, D.M., Porteus, E.L., 1978. Temporal resolution of uncertainty and dynamic choice theory. Econometrica 46(1), 185-200.

Lucas, R.E., 1978. Asset prices in an exchange economy. Econometrica 46: 1429-1445.

Malloy, C.J., Moskowitz, T.J., Vissing-Jørgensen, A., 2009. Long-run stockholder consumption risk and asset returns. The Journal of Finance 64, 2427-2479.

Merton, R.C., 1973. An intertemporal capital asset pricing model. Econometrica 41 (5), 867-887.

Ohlson, J.A., 1995. Earnings, book values, and dividends in equity valuation. Contemporary Accounting Research 11, 661-687.

Pastor L., Veronesi, P., 2003. Stock Valuation and learning about profitability. The Journal of Finance 58, 1749-1789.

Ross, S., 1976. The arbitrage theory of capital asset pricing. Journal of Economic Theory 13, 341-360.

Rubinstein, M., 1976. The valuation of uncertain income streams and the pricing of options. The Bell Journal of Economics 7, 407-425.

Senbet, L.W., Thompson, H.E., 1982. Growth and Risk. Journal of Financial and Quantitative Analysis 27, 331-340.

Yee, K.K., 2008. A Bayesian framework for combining valuation estimates. Review of Quantitative Finance and Accounting 30, 339-354.

Strzalecki, T., 2013. Temporal resolution of uncertainty and recursive models of ambiguity aversion. Econometrica 81(3), 1039-1074. 